\title{
COVID 19- A REVIEW
}

\section{NITISH B ${ }^{1}$, RITIKA ${ }^{2}$, RITIKA $\mathrm{T}^{2}$, CHERIYAN BV $^{3}$ AND JEGANATH $\mathbf{1}^{\mathbf{1}^{*}}$}

1: Department of Pharmaceutics, School of Pharmaceutical Sciences, Vels Institute of Science, Technology And Advanced Studies (VISTAS), Pallavaram, Chennai-600117, India

2: Amar Shaheed Baba Ajit Singh Jujhar Singh Memorial (ASBASJSM) College of Pharmacy, Bela, Ropar-140111, Punjab, India

3: Department of Pharmaceutical Chemistry and Analysis, School of Pharmaceutical Sciences, Vels Institute of Science, Technology And Advanced Studies (VISTAS), Pallavaram, Chennai-600117, India

*Corresponding Author: Dr. S. Jeganath; E-Mail: jeganaths@gmail.com; Mob. No: +919442302356

Received $2^{\text {nd }}$ May 2020; Revised $25^{\text {th }}$ May 2020; Accepted $3^{\text {rd }}$ June 2020; Available online $1^{\text {st }}$ Sept. 2020 https://doi.org/10.31032/IJBPAS/2020/9.9.5184

\begin{abstract}
The introduction and dissemination of 2019 novel coronavirus (2019-nCoV) or the extreme acute respiratory syndrome coronavirus 2 (SARS-CoV-2) is presenting the planet with new public health emergencies. The virus appeared in bats and was transferred to humankind in December 2019 through still unidentified intermediate wildlife in Wuhan, Hubei Province, China. . The disease is spread by combustion or interaction with infectious droplets, and the time of incubation varies between 2 to 14 days. The signs generally include fever, cough, sore throat, shortness of breath, tiredness, malaise and others. The condition is moderate in many other individuals; it can lead to influenza, acute respiratory distress syndrome (ARDS), and multi-organ failure in others (usually the elderly and others with comorbidities). A lot of people are symptomless. The fatality rate of accidents is measured at 2 to 3 per cent. Treatment plan is by specialized genetic examination, by showing the virus in respiratory secretions. Different experimental results involve regular / low counts of white cells with elevated C-reactive protein (CRP). Computerized tomographic chest scanning is ordinarily anomalous except in those without symptoms or minor illness. Treatment is largely supportive; antiviral agent function is yet to be identified. Risk reduction includes residential segregation of suspicious patients as well as those with minor diseases in hospitals to require touch and droplet
\end{abstract}


monitoring, and stringent infection management procedures. The virus is spreading the SARS-CoV and Middle East coronavirus respiratory syndrome (MERS-CoV) quicker than its two predecessors, but has lower fatality. Although unclear is the economic influence of this new outbreak.

\section{Keyword: COVID-19; Corono virus; WHO; Respiration problem}

\section{INTRODUCTION}

As it was then called, the 2019 novel coronavirus (2019-nCoV) or extreme acute respiratory syndrome corona virus 2 (SARS-CoV-2) is quickly spreading from its sources in Wuhan City, Hubei Provincial of China [1]. to the rest of the globe with reports currently documented in dozens of countries. Around 37,27,900 cases of coronavirus disease (COVID-19) and 2,58,300 deaths have been documented up to $06 / 05 / 2020$ [2]. India has so far registered 49,530 cases and 14,498 recovered and 1694 death were reported until 06/05/2020. Children have also been severely infected with low incidence of deaths so far. The virus 'potential path is uncertain. This article provides a view of this emerging virus from a bird's eye. Given the rapidly developing awareness about this virus, readers are encouraged to update himself periodically.

\section{HISTORY}

Coronaviruses become accompanied by positive RNA viruses ranging in size from $60 \mathrm{~nm}$ to $140 \mathrm{~nm}$, with a spike-like projection on its surfaces giving it a crown-like appearance underneath the electron microscope; thus the term coronavirus [3]. There have been several 4 corona viruses in humans, respectively HKU1, NL63, 229E and OC43, which usually cause moderate respiratory disease. Two cases have arisen in almost all of the previous two decades in which trans. The very first event took place in 2002-2003 because if a new $\beta$-generated coronavirus circulating in bats spread to humans via the intermediary community of palm civet cats in Guangdong, China. This virus, known as the severe acute respiratory coronavirus disorder, infected 8,422 people predominantly in China and Hong Kong and caused 916 deaths (11 percent death rate) when it was still contained [4].Nearly a year later, in 2012, the Middle East respiratory coronavirus disease (MERS-CoV), and also bat sources, emerged as the dromedical camel intermediate vector in Saudi Arabia, impacting 2494 people and causing 858 fatalities (death rate 34 percent) [5].

ORIGIN AND SPREAD OF COVID-19 $[1,2,6]$

In December 2019 people started recording severe pneumonia of incurable disease to hospitals in the area in Wuhan, the capital of Hubei communities and a large infrastructure centre in China. Some of the 
originally situations used to have a common link with Huanan's retail seafood community, which sometimes traded livestock. That communication system (established after the SARS epidemic) was activated, and patient respiratory samples for etiological analysis was sent to test laboratory. On 31 December 2019, China announced the outbreak to a World Health Organization and on 1 January, the Huanan seafood market closed. On January 7, the virus was identified as a coronavirus with bat coronavirus homology of $>95$ percent and SARS-CoV comparison of $>70$ per cent. Biological tests from the Huanan seafood industry have been positively tested, indicating the virus originated through there [7]. The number of instances continued to grow quickly, including those who can't get access to the market for live animals, suggesting that there was transmission through human to human [8]. The first fatal occurrence was revealed on 11 January 2020. During most of the Chinese New Year the epidemic was fuelled by massive Chinese immigration.Among other parts of China, other nations (among rapid succession, Thailand, Canada, and Australia) cases were reported of people whom have graduated from Wuhan. On January 20, 2020, communication to health-care workers was established. By 23 January the 11 million Wuhan community was putting beyond lockdown by preventing entries and exits from either the city. This latch-down was rapidly spread to several other regional Hubei towns. Cases of COVID-19 in non-China countries have been established between those with no travel history to China, suggesting local transmission of human-to-human distribution in all those countries [9]. Airports in numerous countries including India placed symptomatic individuals returning from China in observation networks to be detected and established in exclusion and COVID-19 surveillance. This soon became apparent that the infection could propagate from individuals who were sick, even well before symptoms began. Furthermore, nations such as India, that also retrieved their people from Wuhan by independent flights or had travelers returning from China, placed all inhabitants in quarantine for signs of $14 \mathrm{~d}$ and otherwise inspected everyone for both.

Instances helped develop gradually and modelling studies registered an outbreak doubles time of $1.8 \mathrm{~d}$ [10]. Nevertheless, on February 12, China changed its classification of confirmed cases to include both patients with negative / awaiting genetic testing but with COVID-19 surgical, radiological and epidemiological attributes leading to a 15,000 -fold increase in patients in one day [6]. As of 05/03/2020 [2] 96,000 accidents worldwide (80,000 in China) and 87 other nations and international transport 
(696 in the Diamond Princess cruise liner stranded off Japan's coastline) were recorded [2]. It is important to note that while the amount of additional stories in China has significantly declined, they continue gradually risen in many other areas such as South Korea, USA, Italy, and Iran. 20 per cent are in critical condition among those infected, 25 per percent have recovered and 3310 have already died [2] (3013 in China and 297 in other countries). India, which had registered just three cases until 2/3/2020, also experienced an unexpected burst in the cases. By 5/3/2020, 29 cases had been recorded; in Italian visitors and their connections most often in Delhi, Jaipur, and Agra. Most of those cases communications were quarantined.

Such numbers are likely an underestimation of the sick and the dead due to tracking and testing shortcomings. Since the SARS-CoV-2 derived from bats, there is confusion about the intermediate animal which it transferred to humans. The latest offenders include pangolins and snakes.

\section{Epidemiology and Pathogenesis $[10,11]$}

These are open to all ages. Infection is spread by large droplets that are produced by merely a symptom patients throughout sneezing and coughing, but may also happen from immune compromised people and this is before indications start [9]. Research have already shown elevated infection rates in the nostril comparison to the throat, with no difference in viral load between indicative and undiagnosed individuals [12]. In just as long as the complications continue but even on clinical rehabilitation, patients can be contagious [6].These contaminated droplets will scatter 1-2 $\mathrm{m}$ over substances and deposition. In ideal environmental conditions, the virus will stay viable on surfaces for days but is killed in under a minutes by specific disinfectants, such as sodium hypochlorite, hydrogen peroxide, etc. [13]. The virus is also involved throughout the bowel and source of water waste and corresponding dissemination is also suspected by aerosolization / feco oral route [6]. Under current information, there was no explanation of transplacental transmission from expectant mothers to their fetus [14]. Paediatric disease attributable to post-birth dissemination is nevertheless described [14]. The incubation time [median $5 \mathrm{~d}$ ] ranges from 2 to $14 \mathrm{~d}$. Studies have established angiotensin receptors 2 (ACE2) as both the receptor by which the virus reaches the mucosal respiratory system [11].

In different modeling studies [11] the simple case replication rate $(\mathrm{BCR})$ is reported to extend from 2 to 6.47. In addition, the SARS BCR was 2 and 1.3 for the 2009 H1N1 pandemic flu ${ }^{[2]}$.

Clinical Features $[8,15-18]$ 
COVID-19's clinical characteristics range from severely immunocompromised to acute respiratory distress syndrome, including dual-organ failure. Fever (not in all), cough, sore throat, fever, exhaustion, anxiety, myalgia, and breathlessness are typical health characteristics. Oral thrush was identified, too. These are thus distinguished from many other airborne pathogens. For a segment of patients the disease can progresses to pneumonia, respiratory failure, and death by the end of the first week [15]. The mean time between starting treatment to shortness of breath was $5 \mathrm{~d}$, involuntary confinement $7 \mathrm{~d}$, and severe respiratory distress (ARDS) syndrome $8 \mathrm{~d}$. Throughout the published study, this need for accident and emergency treatment was present throughout 25-30 percent of impacted patients. Encountered consequences involved avulsion fracture to the heart, ARDS, trauma and acute kidney damage. Regeneration beginning in week $2^{\text {nd }}$ or $3^{\text {rd }}$. For all those who survived the mean period of stay in the hospital was $10 \mathrm{~d}$. Adverse results and death are much more frequent in older people as well as those with ongoing non-morbidities $(50-75 \%$ of catastrophic cases). The death rate increased from $4 \%$ to $11 \%$ in injured adult patients. It is calculated that the average event fatality rate ranges between 2 and 3 percent [2]. Unfortunately, illness has been confirmed to be milder in patients outside of Hubei province than those in Wuhan [17]. Likewise, in patients outside China, the frequency and fatal accident rate of cases was stated to be milder [6]. It can either be due to sampling discrimination in which the instances identified from Wuhan involved only the extreme cases or attributable to the Asian population in terms genetic disposition to both the virus due to the increased production of ACE2 inhibitors on the pulmonary mucosa [11].

Disease has also been confirmed to be slightly gentler in newborns, babies and children than those in their adult equivalents. Around 19 January and 7 February there had been 14 males and 20 females in a sequence of 34 children reported to a hospitals in Shenzhen, China. The median age was $8 \mathrm{y}$ $11 \mathrm{mo}$ as well as the disease were related to a member of the family in 28 babies, and 26 babies had transport / domicile background to China's Hubei provinces. All of the sufferers were either symptomless (9 percent) or had minor illness. No serious or vital cases have been identified. Fever (50 percent) and cough (38 per cent) were the most serious symptoms. Both patients recovered with symptomatic treatment, and no deaths were registered $[\mathbf{1 9}, \mathbf{2 0}]$.

\section{Diagnosis [21]}

A suspected case is classified as something with fever, sore throat and cough that has travel past to China or any other area with regular local spread or contact without 
patients with associated travel records, including those with documented COVID-19 infection. Instances can be almost symptomless, even without fever at times. A reported case is a suspect case for such a positive molecular examination. Multiple biochemical studies on pulmonary specimens (bone density scan / oropharyngeal swab / sputum / implantable pulmonary cardioverter and bronchoalveolar wash) are carried out in simple assessment. Virus can also be found in the urine, and blood in extreme cases. It is worth noting that the commercially available multiplex PCR boards will not contain the COVID-19. There will be currently no market studies available, either. For a suspicious case for India, the correct sample needs to be submitted to approved test laboratories in India or to the National Virology Institute in Pune. Commercial services begin to become available as the disease continues. Many lab examinations are generally non-specific. The number of white cells normally is average or small. Lymphopenia might occur; serious illness has been correlated with a lymphocyte count $<1000$. The number of platelets is commonly regular or slightly weak. CRP and ESR are frequently heightened but typically the levels of procalcitonin are regular. A high level of procalcitonin can suggest a co-infection with the bacteria.
The X-ray in the chest (CXR) normally reveals bilateral penetration which can be rare in early illness. The CT is closer and much more precise. CT imagery typically reveals infiltrations, distortion of ground glass and convergence of sub-segments. It is also anomalous in symptomless patients / patients who have no established proof of lower participation in the respiratory tract. In addition, in suspicious cases of inaccurate molecular diagnosis, an irregular CT scan was used to diagnose COVID-19; several of these patients had positive molecular results on repeated testing [22].

\section{Differential Diagnosis [21]}

The differentiated classification covers all categories of pulmonary viral infections atypical species (mycoplasma, chlamydia), and viruses. COVID-19 cannot be scientifically isolated from both of these pathogens or by routine laboratory testing. Otherwise the history of travel becomes significant. The traveling past will therefore appear meaningless as the virus spreads.

\section{Treatment $[22,23]$}

Treatment is generally emblematic and compassionate. The very first approach is to establish sufficient separation (mentioned later) to avoid exposure to several other partners, clinicians and health-care staff. Mild disease must be treated at homes with advice on symptoms of risk. The normal values are digestion and diet management, including fever and cough regulation. In 
reported cases the daily use antibiotics and antivirals like oseltamivir should be discouraged. For low oxygen patients it is suggested that breathing is given by respiratory prongs, face mask, high flow nasal cannula (HFNC) or semi-invasive breathing. Mechanical breathing can be required, and sometimes even additional support for body membranes oxygen. In others, maintenance renal therapy can be necessary. Antibiotics and antimicrobials are necessary when non-infections are presumed or confirmed. The position of corticosteroids is unsubstantiated; although the latest international opinion and the World Health Organization advise that their use, Chinese recommendations suggest brief-term corticosteroid counseling in COVID-19 ARDS [24, 25]. WHO has issued comprehensive guidance on handling emergency treatment for COVID-19 [26]. As for now, there is no licensed medication for COVID-19. Depending on familiarity with SARS and MERS, antiviral medications such as ribavirin, lopinavir-ritonavir, were used.Patients diagnosed with lopinavir-ritonavir with ribavirin had improved results in a retrospective monitoring trial of patients with SARS relative towards those diagnosed with ribavirin alone [15].

In the case sequence of 99 hospitalized patients with Wuhan COVID-19 infection, ventilation was provided to $76 \%$, semi-invasive ventilation to $13 \%$, mechanical ventilation to $4 \%$, extracorporeal membrane oxygenation (ECMO) to $3 \%$, continuous renal replacement therapy (CRRT) to 9\%, antibiotics to $71 \%$, antifungals to $15 \%$, glucocorticoids to $19 \%$ and glucocorticoids to $9 \% .75$ per cent of patients prescribed antiviral treatment comprising of oseltamivir, ganciclovir and lopinavir-ritonavir. The semi-invasive breathing period was 4-22 d [median $9 \mathrm{~d}$ ], and 3-20 d [median $17 \mathrm{~d}$ ] intubation. All children survived with routine therapy throughout the case likely of children previously mentioned, and didn't require comprehensive care [17]. In fact, guidelines on the use of conventional Chinese herbs can be found in the Chinese Guidelines [27, 28, 29].

\section{Prevention [30]}

Because no therapies for the above disease are available at the moment, avoidance is key. Semi-specific characteristics of the disease, infectivity much before the initiation of signs during the incubation phase, dissemination from asymptomatic individuals, lengthy incubation time, virulence factors for mucous substances including the conjunctive, extended existence of the disease and spread even when surgical rehabilitation make it almost impossible to deter this infection. 
It is advised that you separate confirmed or suspicious cases of minor illness at home. Once in the similar environment as the patient, nurses will be encouraged to wear a surgical mask and also use hand washing every 15-20 min. The biggest concern of COVID-19 is exposure to medical care staff. 21 per cent of those involved became medical care staff in the 2002 SARS outbreak [31]. About 1500 medical professionals in China have been diagnosed with six deaths so far. The physician who initially cautioned of the infection has since expired. Protecting healthcare professionals is critical for maintaining quality of treatment and avoiding spread of infection to many other patients. Patients should always be housed in or co-hosted in different quarters. In particular, negative pressure chambers are not required. Rooms, materials, appliances should always be decontaminated with sodium hypochlorite at frequent intervals ideally. Medical care staff will be issued with suit-tested N95 protective clothing and glasses and safety suits. Precautionary measures for airborne transmission should always be taken during operations which produce aerosols including intubation, suction, and tracheostomy. In the production of COVID-19 complications all interactions with medical care staff will be tracked. Whenever patients are afebrile for atleast $3 d$ and also have two successive negative molecular tests at $1 \mathrm{~d}$ screening time, they may be released from isolation. This advice is distinct from global pandemic in which respondents were asked to continue employment / school for 24 hours or day 7 of influenza until afebrile. Negative molecular monitoring was not a pre-condition for discharge.

Citizens will be told at population level to discourage busy areas and to delay semi-essential transportation to locations of constant broadcast. They will also be told to improve coughing grooming by coughing in jacket / cloth instead of hand and regularly exercise hand hygiene every $15-20 \mathrm{~min}$. Surgical masks should be given on people with respiratory problems. Decent people's use masks in public places has not been proven to safeguard toward breathing virus infections and is not specifically recommended by WHO. China is now contemplating laws prohibiting the selling and trafficking of wild animals [32].

The international reaction has also been magnificent. Originally, there had been major travel prohibitions to China, and citizens withdrawing from China / deemed uninhabitable from China are now being monitored for health signs, separated and COVID-19 screened for 2 wks, and although asymptomatic. Now although, these travel bans have extended to many nations with accelerated worldwide dissemination of the virus. It is not clear if 
such efforts would contribute to stopping the propagation of viruses. A candidate vaccination is currently under production.

\section{Practice Points from an Indian Perspective}

The chance for coronavirus in India is less at the time of writing this post. But that can improve over the next couple of weeks. This is therefore advised that healthcare professionals consider international records among all patients with respiratory problems and maybe some overseas travel throughout the past 2 wks and also some interaction regarding globally traveling sick persons. They would establish an outpatient hospital emergency medical program for patients with respiratory illness, as well as provide everyone a clear surgical mask to use. They will also use breathing masks when treating these patients and regularly exercise hand hygiene. Confirmed cases will be sent to insulation and examination centers approved by the government (at such a time, it is Kasturba hospital in Mumbai). Professional test kits are now available in India. Patients hospitalized with extreme pneumonia and acute respiratory distress syndrome will be diagnosed and put under touch and droplet separation for transportation records. Regular substrate waste disposal is necessary. If logistics allow, and if no pathogen is detected, referral that specimens for SARS-CoV-2 processing, they should always be screened for etiology using multiplex PCR panels. Both physicians will keep up-to-date on current trends like global epidemic transmission. Throughout this time, non-essential overseas journeys will be stopped. People should stop circulating rumors and misconceptions about both the disease and attempt to reduce public panic and anxiety

\section{CONCLUSION}

This latest virus epidemic has threatened China's cultural, medical, and environmental health resources, and, towards some degree, its neighbors, especially, from other countries. Time alone can say how this virus affects our lives here in India. More so, potential occurrences of zoonotic-origin viruses and pathogens are expected to occur. Hence, with the exception of curbing this epidemic, attempts will be undertaken to formulate systematic steps to deter potential zoonotic cause outbreaks.

\section{REFERNCES}

[1] Wang C, Horby PW, Hayden FG, Gao GF. A novel coronavirus outbreak of global health concern. Lancet. 2020

[2] Coronavirus Outbreak. Available at: https://www.worldometers.info /coronavirus/. Accessed 23 Feb 2020

[3] Richman DD, Whitley RJ, Hayden FG. Clinical Virology, 4th ed. Washington: ASM Press; 2016. 
[4] Chan-Yeung M, Xu RH. SARS: epidemiology. Respirology. 2003; 8:S9-14.

[5] Middle East Respiratory Syndrome Coronavirus.

Available at: https://www.who.int/emergencies/m ers-cov/en/. Accessed 16 Feb 2020.

[6] World Health Organization. Situation reports. Available at: https://www.who.int/emergencies/di $\underline{\text { seases/novel-coronavirus-2019/situatio }}$ n-reports/. Accessed 22 Feb 2020

[7] Xinhua. China's CDC detects a large number of new coronaviruses in the South China seafood market in Wuhan. Available at: https://www.xinhuanet.com /2020-01/27/c 1125504355.htm. Accessed 20 Feb 2020.

[8] Huang C, Wang Y, Li X, et al. Clinical features of patients infected with 2019 novel coronavirus in Wuhan, China. Lancet. 2020; 395: 497-506.

[9] Rothe C, Schunk M, Sothmann P, et al. Transmission of 2019-nCoV infection from an asymptomatic contact in Germany. N Engl J Med. 2020. https://doi.org 110.1056/NEJMc2001468.

[10]Li Q, Guan X, Wu P, et al. Early transmission dynamics in Wuhan, China, of novel coronavirus-infected pneumonia. $\mathrm{N}$ Engl $\mathrm{J}$ Med.
2020. https://doi.org/

10.1056/NEJMoa2001316.

[11]Cheng ZJ, Shan J. 2019 novel coronavirus: where we are and what we know. Infection. 2020: 1-9. https://doi.org/10.1007/s15010 -020-01401-y.

[12]Zou L, Ruan F, Huang $\mathrm{M}$, et al. SARS-CoV-2 viral load in upper respiratory specimens of infected patients. N Engl J Med. $2020 . \quad$ https://doi.org/10.1056 NEJMc2001737.

[13]Kampf G, Todt D, Pfaender S, Steinmann E. Persistence of coronaviruses on inanimate surfaces and its inactivation with biocidal agents. J Hosp Infect. 2020 Feb 6. pii: S0195-6701(20) 30046-3.

[14]Chen H, Guo J, Wang C, et al. Clinical characteristics and intrauterine vertical transmission potential of COVID-19 infection in nine pregnant women: a retrospective review of medical records. Lancet.

2020. https://doi.org/10.1016/S0140-67 36 (20)30360-3.

[15]Chen N, Zhou M, Dong X, et al. Epidemiological and clinical characteristics of 99 cases of 2019 novel coronavirus pneumonia in Wuhan, China: a descriptive study. Lancet. 2020; 395: 507-13. 
[16] Wang D, Hu B, Hu C, et al. Clinical characteristics of 138 hospitalized patients with 2019 novel coronavirus-infected pneumonia in Wuhan, China. JAMA. 2020. https://doi.org/10.1001/jama.202 $\underline{0.1585}$.

[17] Xu XW, Wu XX, Jiang XG, et al. Clinical findings in a group of patients infected with the 2019 novel coronavirus (SARS-Cov-2) outside of Wuhan, China: retrospective case series. BMJ. 2020; 368: m606.

[18] Wang XF, Yuan J, Zheng YJ, et al. Clinical and epidemiological characteristics of 34 children with 2019 novel coronavirus infection in Shenzhen. [Article in Chinese]. Zhonghua Er Ke Za Zhi. 2020; 58: E008.

[19] Chen F, Liu ZS, Zhang FR, et al. First case of severe childhood novel coronavirus pneumonia in China. Zhonghua Er Ke Za Zhi. 2020; 58: E005

[20]Zeng LK, Tao XW, Yuan WH, Wang J, Liu X, Liu ZS. First case of neonate infected with novel coronavirus pneumonia in China. Zhonghua Er Ke Za Zhi. 2020; 58: E009.

[21] Jin YH, Cai L, Cheng ZS, et al. A rapid advice guideline for the diagnosis and treatment of 2019 novel coronavirus [2019-nCoV] infected pneumonia [standard version]. Mil Med Res. 2020;7:4

[22] Huang P, Liu T, Huang L, et al. Use of chest $\mathrm{CT}$ in combination with negative RT-PCR assay for the 2019 novel coronavirus but high clinical suspicion. Radiology.

2020. https://doi.org/10.1148/ radiol.2020200330.

[23]Chen Z-M, Fu J-F, Shu Q, et al. Diagnosis and treatment recommendations for pediatric respiratory infection caused by the 2019 novel coronavirus. World J Pediatr. 2020:

1-7. https://doi.org/10.1007/s12519-02 0-00345-5.

[24]Russell CD, Millar JE, Baillie JK. Clinical evidence does not support corticosteroid treatment for $2019-\mathrm{nCoV}$ lung injury. Lancet. 2020; 395: 473-5.

[25]Zhao JP, Hu Y, Du RH, et al. Expert consensus on the use of corticosteroid in patients with 2019-nCoV pneumonia. Zhonghua Jie $\mathrm{He} \mathrm{He} \mathrm{Hu}$ Xi Za Zhi. 2020; 43: E007.

[26] WHO. Clinical management of severe acute respiratory infection when novel coronavirus $[\mathrm{nCoV}]$ infection is suspected. Available at: https://www.who.int/publications-d etail/clinical-management-of-severe-ac ute-respiratory-infection-when-novelco 
ronavirus-[ncov]-infection-is-suspected. Accessed 9 Feb 2020.

[27] Holshue ML, DeBolt C, Lindquist S, et al. First case of 2019 novel coronavirus in the United States. N Engl J Med. 2020. https://doi.org/10.1056/NEJMoa 2001191.

[28] Zhang L, Liu Y. Potential interventions for novel coronavirus in China: a systemic review. J Med Virol. 2020. https://doi.org/ 10.1002/jmv.25707.

[29] Multicenter Collaboration Group of Department of Science and Technology of Guangdong Province and Health Commission of Guangdong Province for Chloroquine in the Treatment of Novel Coronavirus Pneumonia. [Expert consensus on chloroquine phosphate for the treatment of novel coronavirus pneumonia]. [Article in Chinese] Zhonghua Jie $\mathrm{He} \mathrm{He} \mathrm{Hu}$ Xi Za Zhi. 2020; 43: E019.

[30] World Health Organization. Coronavirus disease [COVID-19] Technical Guidance: Infection Prevention and Control. Available at: https://www.who.int/emergencies/di seases/novel-coronavirus-2019/technic al-guidance/infection-prevention-and-c ontrol. Accessed 20 Feb 2020.

[31]Chang D, Xu H, Rebaza A, Sharma L, Dela Cruz CS. Protecting health-care workers from subclinical coronavirus infection. Lancet Respir Med. 2020. https://doi.org/10.1016/S2213-26 $\underline{00(20) 30066-7 .}$.

[32] Li J, Li J, Xie X, et al. Game consumption and the 2019 novel coronavirus. Lancet Infect Dis. 2020. https://doi.org/10.1016/S1473-30 99(20) 30063-3 